\title{
Prospective study of the disadvantage of people from ethnic minority groups applying to medical schools in the United Kingdom
}

\author{
I C McManus, Peter Richards, S L Maitlis
}

\begin{abstract}
To assess whether the ethnic origin of applicants affects their likelihood of being accepted into medical school in the United Kingdom the outcome for the 2399 applicants who applied to read medicine at university in 1986 and included St Mary's Hospital Medical School as one of their five choices was studied prospectively. Altogether 2040 of the 2399 applicants were British (United Kingdom) nationals, constituting $\mathbf{2 4 \cdot 7 \%}(\mathrm{n}=\mathbf{8 2 4 9})$ of all home applicants for medicine in 1986, and 1971 of them with postal addresses in the United Kingdom were sent questionnaires asking about their ethnic origin, whether English was their first language, and about their attitudes to ethnic monitoring. A total of 1817 $(92.2 \%)$ applicants returned the questionnaire, 401 $(22.6 \%)$ saying that they were from an ethnic minority group and $393(21.6 \%)$ having non-European surnames. Multiple logistic regression identified 11 significant predictors of successful application, of which grades at $\mathbf{O}$ and $\mathbf{A}$ level, application after $\mathbf{A}$ levels, and date of application were the most important. After taking these four variables into account the predicted acceptance rates for home students on the basis of their application forms alone were $47.8 \%$ for white applicants and $35.6 \%$ for applicants from ethnic minority groups compared with actual acceptance rates of $49 \cdot 6 \%$ and $27 \cdot 3 \%$, respectively. The difference in success of white and non-white applicants could partly but not entirely be explained by differences in the characteristics considered to be important in a professional context by selectors during shortlisting of candidates: academic ability, interests, and contribution to the community. No differences in the success rate of applicants from ethnic minority groups to individual medical schools could be identified.
\end{abstract}

More research is needed to discover how perceptions of professional suitability are assessed from application forms and interviews.

St Mary's Hospital Medical School, Imperial College of Science, Technology, and Medicine, London W2 1PG I C McManus, MD, senior lecturer in psychology applied to medicine

Peter Richards, FRCP, dean

S L Maitlis, BSC, research assistant

Correspondence to: $\mathrm{Dr}$ McManus.

BrMed f 1989;298:723-6

\section{Introduction}

Admission to medical school in the United Kingdom is highly competitive, and medical students are among the highest qualified of all university entrants. In October 1986, 9972 people applied to British medical schools: 8249 applicants were "home" candidates, of whom $3841(46 \cdot 6 \%)$ were accepted.'

In a prospective study predicting success in a sample of applicants to British medical schools for admission in October 1981 we found that significant predictors of success were higher average grades at $\mathrm{O}$ and $\mathrm{A}$ level, greater numbers of $\mathrm{O}$ and $\mathrm{A}$ levels, early application to the Universities Central Council on Admissions, and having a medically qualified parent. ${ }^{2}$ In a supplement- ary study we also found that applicants from ethnic minority groups (assessed by taking a non-European surname as an indicator of ethnic origin) were less likely to be accepted, even after known predictors had been taken into account, and that the difference could be explained by the fact that applicants from ethnic minority groups had lower assessments of interests or less evidence of contribution to the community. ${ }^{3}$

The Race Relations Act 1976 makes discrimination illegal on the basis of ethnic origin. In November 1986 the Commission for Racial Equality initiated a formal investigation into the selection policy of one medical school and concluded that the school had "directly discriminated on racial grounds." 45

In September 1985 we started our second prospective study of the selection of medical students for admission in October 1986 not only obtaining similar information to that for the 1981 cohort but also asking candidates to describe their own ethnic origins. A previous study that used indirect measures of ethnic origin such as surname may have been inaccurate ${ }^{6}$ principally because applicants of West Indian descent typically have European surnames.

We report the overall results of our audit of selection for admission in October 1986, comparing our findings with those of 1981 and paying particular attention to the outcome of applications by candidates from ethnic minority groups.

\section{Methods}

All applicants who as one of their five choices on the application form had applied between 1 September and 15 December 1985 for admission to St Mary's Hospital Medical School and had a United Kingdom postal address were included in the questionnaire survey. Within a week or so of receipt of their application candidates were sent a lengthy questionnaire asking, among other things, about social and educational background. Seven questions asked about ethnic origin and place of birth of candidates and their parents, whether English was the first language, and the age at which it was first spoken, and about attitudes to ethnic monitoring. Copies of the questionnaire are available on request from ICM.

Applicants were informed that the questionnaire was entirely for educational research and that its contents were strictly confidential and would not be available to people concerned with the selection itself. A stamped return envelope was included with the questionnaire. A second copy of the questionnaire was sent if no reply was received within four weeks, and a third copy if no reply had arrived in a further four weeks.

The candidates were shortlisted by four people; an extensive description of the structure of preselection 
judgments and the reliability of shortlisting is given elsewhere. ${ }^{78}$ Each candidate was rated on nine separate scales, from which measures were derived of his or her academic ability, interests, and contribution to the community.

Additional information on candidates was obtained from the application form. $\mathrm{O}$ and $\mathrm{A}$ level results were summarised as the number of exams taken and the mean grade obtained and were scored as five points for an $A$ grade, four for a $B$, three for a $C$, two for a $D$, one for an $\mathrm{E}$, and zero for an $\mathrm{O}$ or $\mathrm{F}$ grade. Exams that had been resat were scored at the highest grade obtained and counted only once in the overall number. A level results for examinations taken after application were linked with the other information.

Surnames of applicants were classified as European or non-European by two people (ICM and DNJL, a medical registrar with experience of working in the Third World), with $96 \%$ agreement. A non-European surname was defined as either person classifying the surname as non-European.

The final destinations of candidates were obtained from the Universities Central Council on Admissions, as was information about conditional or unconditional offers at each of the medical schools to which they had applied.

Unless stated otherwise all variables are defined in the same way as those described in our analysis of the 1981 cohort. 2910

We used the statistical package for the social sciences $\mathrm{X}$ (SPSS X)" for descriptive, univariate, and multivariate analyses and general linear interactive modelling $^{12}$ for multiple logistic regressions, which assessed significance by backwards elimination from a saturated main effects model. Missing values for variables included in multivariate analyses were replaced by population means. The log odds ratio for the effect of each variable on selection was derived directly from its coefficient in the logistic regression and the odds ratio calculated by exponentiation.

\section{Results}

In total 2399 people, of whom 2040 were British (United Kingdom) nationals, applied to the Universities Central Council on Admission for admission in October 1986 and included St Mary's Hospital Medical School as one of their five choices. A total of 2209 of these 2399 applicants who had applied to the council by the official closing date of 15 December 1985 and had postal addresses in the United Kingdom were included in the questionnaire survey. They included 1971 British nationals who were sent a questionnaire; 1837 $(93 \cdot 2 \%)$ of them returned the questionnaire, all but 20 answering the question on ethnic origin.

Of the 2040 British nationals (including late applicants), $1198(58.7 \%)$ received at least one offer from a medical school and $871(42 \cdot 7 \%)$ received confirmed offers for admission in October 1986, having fulfilled all requirements for entry.
Analyses in this paper are confined to British nationals alone and "offer" or "acceptance" refers to any medical school, not only to St Mary's Hospital Medical School, although all applicants surveyed had included St Mary's as one of their five choices.

\section{ETHNIC ORIGINS}

Altogether $411(22 \cdot 6 \%)$ of the 1817 United Kingdom nationals answering the question on ethnic origin described themselves as coming from an ethnic minority. A total of $393(21 \cdot 6 \%)$ of the 1817 British nationals had non-European surnames, compared with $50(32.5 \%)$ of the 154 British nationals who did not return the questionnaire or describe their ethnic origin, a significant difference $\left(\chi_{*}^{2}=9.57, \mathrm{df}=1, \mathrm{p}<0.01\right)$. Applicants from ethnic minority groups had lower rates of offers and acceptances; they also had lower grades at $\mathrm{O}$ and $\mathrm{A}$ level and had applied later (table I). The proportion of candidates who eventually obtained A level grades equivalent to BCC, the lowest grades at which a candidate has a realistic chance of acceptance at a British medical school, differed substantially between ethnic groups (table I).

\section{PREDICTION OF SUCCESS}

Table II shows simple descriptive statistics for variables studied in 1981 and 1986 in the 2040 British nationals. Self classified ethnic origin was not available in 1981 and therefore to allow direct comparison table II also gives classification by surname. Entrants in 1986 were more likely to be women, less likely to come from a medical family, less likely to be mature students, more than twice as likely to have a non-European surname, and less likely to come from social class I $(47 \cdot 5 \%, 35 \cdot 1 \%, 13 \cdot 3 \%$, and $4 \cdot 1 \%$ coming from social classes I, II, III, and IV and V, compared with $54.3 \%$, $32 \cdot 6 \%, 11 \cdot 1 \%$, and $2.0 \%$ in 1981 ). Entrants in 1986 had also taken more $\mathrm{O}$ levels, were more likely to have taken A level mathematics, were less likely to have applied after A level or to have applied previously, and had ranked their choices more - that is had bracketed their choices less - on their application forms. In 1986 physics was taken by only $70 \%$ of entrants compared with $90 \%$ in 1981 .

Multiple logistic regression with general linear interactive modelling ${ }^{12}$ was used to predict entry to any medical school in the United Kingdom for the 2040 British nationals in relation to 24 demographic variables that had been considered in 1981. Backwards elimination of variables means that variables are significant after accounting for others occcurring earlier in the prediction equation. Table II shows the order of significance of variables in the equation, as well as the mean and standard deviation (or percentage) of accepted and rejected candidates on each variable and a univariate comparison of these statistics.

Eleven variables significantly predicted acceptance in 1986. Seven variables (mean grade and number of $O$ and A levels taken, date of application, being from a medical family, and having a non-European surname

TABLE I-Self described ethnic origin and success of applicants to medical school in 1986. Data from 1981 cohort classified according to surname are shown for comparison

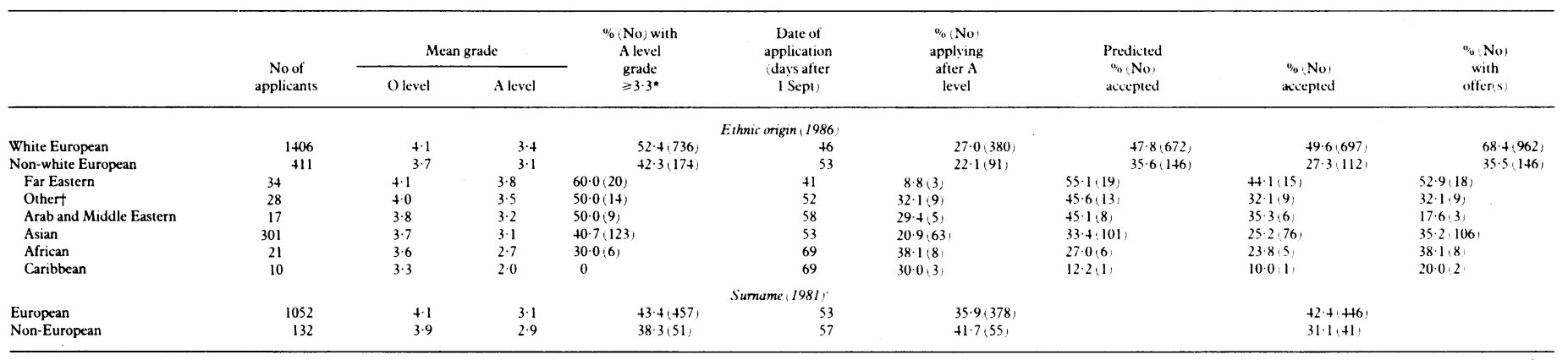




\begin{tabular}{|c|c|c|c|c|c|c|c|c|c|c|}
\hline \multirow{2}{*}{$\begin{array}{l}\text { Order } \\
\text { of } \\
\text { entry }\end{array}$} & \multirow[b]{2}{*}{ Variable } & \multicolumn{3}{|c|}{1986} & \multicolumn{2}{|c|}{1981} & \multicolumn{3}{|c|}{1986} & \multirow{2}{*}{$\begin{array}{c}\text { Odds ratio of } \\
\text { acceptance in } \\
1981\end{array}$} \\
\hline & & $\begin{array}{l}\text { Entrants } \\
(\mathrm{n}=871)\end{array}$ & $\begin{array}{c}\text { Rejects } \\
(\mathrm{n}=1169)\end{array}$ & $\begin{array}{l}\text { Entrants } v \\
\text { rejects }\{p \text { value }\rangle\end{array}$ & $\begin{array}{l}\text { Entrants } \\
(\mathrm{n}=487)\end{array}$ & $\begin{array}{l}\text { Rejects } \\
(\mathrm{n}=697)\end{array}$ & $\begin{array}{l}\text { Odds ratio of } \\
\text { acceptance }\end{array}$ & $\begin{array}{l}\text { Significance } \\
\text { (p value) }\end{array}$ & $\begin{array}{l}95 \% \text { Confidence } \\
\text { interval }\end{array}$ & \\
\hline 1 & A level grade obtained & $+2(0.7)$ & $2 \cdot 6(1 \cdot 0)$ & $<0.001$ & $+0(0.7)$ & $2 \cdot 3(1 \cdot 1)$ & 9.3 Per mean grade & $<0.001$ & $7 \cdot 7$ to 11.3 & $8 \cdot 2$ \\
\hline 2 & O level grade obtained & $+3(0.5)$ & $3 \cdot 7(0 \cdot 7)$ & $<0.001$ & $+3(0.5)$ & $3 \cdot 8(0 \cdot 6)$ & 3.5 Per mean grade & $<0.001$ & $2 \cdot 6$ to 4.5 & $2 \cdot 2$ \\
\hline 3 & Application after A level (\%) & $30 \cdot 2$ & $25 \cdot 4$ & $<0.05$ & 39.0 & $34 \cdot 9$ & 2.6 & $<0.001$ & 1.9 to 3.4 & $1 \cdot 2$ \\
\hline 4 & Date of application to UCCA (days after 1 Sept) & $4 \cdot 6(21 \cdot 5)$ & $62 \cdot 9(32 \cdot 9)$ & $<0.001$ & $45.3(21.6)$ & $60 \cdot 7(25 \cdot 3)$ & 1. 6 Per 28 days earlier & $<0.001$ & 1.4 to 1.9 & $1 \cdot 4$ \\
\hline \multirow[t]{2}{*}{5} & From an ethnic minority $(\%)^{\star}$ & $13 \cdot 8$ & $29 \cdot 7$ & $<0.001$ & & & 2.7 If not from minority & $<0.001$ & $1.910 \quad 3.8$ & \\
\hline & Non-European surname $(\%)$ & $1+1$ & $29 \cdot 4$ & & $8 \cdot 4$ & $13 \cdot 1$ & & & & \\
\hline 6 & No of medical schools on UCCA form & $4.95(0.24)$ & $+85(0.45)$ & $<0.001$ & $4.97(0.20)$ & $4.94(0.35)$ & 2.1 Per medical school & $<0.001$ & $1 \cdot+$ to $3 \cdot 2$ & $1 \cdot 3$ \\
\hline 7 & Mature applicant $(\%)$ & $6 \cdot 4$ & $15 \cdot 8$ & $<0.001$ & $8 \cdot 3$ & $19 \cdot 3$ & $2 \cdot 2$ If not mature applicant & $<0.005$ & 1.4 to 3.6 & $2 \cdot 4$ \\
\hline 8 & No of A levels taken & $3.2(0.5)$ & $3 \cdot 1(0.5)$ & $<0.001$ & $3 \cdot 2(0 \cdot 5)$ & $3 \cdot 1(0.5)$ & $1+$ Per A level & $<0.05$ & 1.1 to 1.8 & 1.8 \\
\hline 9 & Use of bracketing on UCCA form & $4.6(0.8)$ & $+5(0 \cdot 9)$ & $<0.05$ & $4 \cdot 2(1 \cdot 1)$ & $4 \cdot 0(1 \cdot 3)$ & $2 \cdot 1$ For all first equal $v$ ranked & $<0.05$ & $1 \cdot 1$ to $4 \cdot 0$ & $1 \cdot 0$ \\
\hline 10 & No of O levels taken & $9.9(2.0)$ & $9 \cdot 1(2 \cdot 6)$ & $<0.001$ & $9 \cdot 3(2 \cdot 2)$ & $8 \cdot 2(3 \cdot 2)$ & $1 \cdot 1$ Per O level & $<0.05$ & $1 \cdot 0$ to $1 \cdot 2$ & $1 \cdot 2$ \\
\hline 11 & From a medical family (\%) & 16.9 & $15 \cdot 1$ & NS & 19.9 & $15 \cdot 1$ & 1.5 & $<0.05$ & $1 \cdot 1$ to $2 \cdot 2$ & $1 \cdot 7$ \\
\hline 12 & Previous application & $14 \cdot 5$ & $11 \cdot 1$ & $<0.05$ & $22 \cdot 6$ & $20 \cdot 4$ & 1.6 If no previous application & NS & & 1.3 \\
\hline 13 & Female applicant (\%) & $45 \cdot 7$ & $45 \cdot 9$ & NS & $40 \cdot 2$ & $35 \cdot 7$ & $1 \cdot 1$ & NS & & $1 \cdot 1$ \\
\hline 14 & No from sixth form to university each year & $66 \cdot 9(48 \cdot 2)$ & $62 \cdot 2(55 \cdot 4)$ & NS & $57 \cdot 1(36 \cdot 5)$ & $53 \cdot 9(34 \cdot 9)$ & 0.9 Per 10 pupils & NS & & 1.0 \\
\hline 15 & Total No of choices on UCCA form & $4.99(0 \cdot 10)$ & $4.98(0.17)$ & $<0 \cdot 1$ & $4.96(0.35)$ & $4.98(0.13)$ & 0.7 Per choice & NS & & $1 \cdot 1$ \\
\hline 16 & No of London schools on UCCA form & $3 \cdot 2(1 \cdot 4)$ & $3.5(1 \cdot 3)$ & $<0.001$ & $3.5(1.3)$ & $3 \cdot 8(1 \cdot 3)$ & 1.0 Per school & NS & & $1 \cdot 0$ \\
\hline 17 & Private sector education (\%) & $54 \cdot 2$ & $41 \cdot 1$ & $<0.001$ & $51 \cdot 1$ & +4.9 & 1.0 If private sector & NS & & $0 \cdot 7$ \\
\hline 18 & Biology A level taken $(\%)$ & $75 \cdot 2$ & 77.9 & NS & 74.4 & $81 \cdot 0$ & $1 \cdot 0$ & NS & & $1 \cdot 2$ \\
\hline 19 & Mathematics A level taken (\%) & $60 \cdot 2$ & $50 \cdot 5$ & $<0.001$ & $43 \cdot 7$ & $36 \cdot 0$ & $1 \cdot 1$ & NS & & 0.8 \\
\hline 20 & Registrar general's social class & $1.8(0.9)$ & $2 \cdot 0(1 \cdot 0)$ & $<0.001$ & $1.7(0.8)$ & $1 \cdot 8(0 \cdot 8)$ & 1.0 Per class lower & NS & & 1.0 \\
\hline 21 & Oxford or Cambridge chosen (\%) & $21 \cdot 1$ & 3.5 & $<0.001$ & $20 \cdot 3$ & $3 \cdot 3$ & 1.0 & NS & & 1.6 \\
\hline 22 & No in sixth form & $258(224)$ & $266(363)$ & NS & $228(154)$ & $222(1+2)$ & 1.0 Per 100 pupils & NS & & $0 \cdot 9$ \\
\hline 23 & From north of Britain (\%) & $15 \cdot 6$ & 13.9 & NS & $15 \cdot 6$ & 13.9 & 1.0 & NS & & $1 \cdot 3$ \\
\hline 24 & $\%$ Of sixth form to university & $29 \cdot 3(16 \cdot 7)$ & $26 \cdot 4(16 \cdot 9)$ & $<0.001$ & $26 \cdot 5(11 \cdot 8)$ & $25 \cdot 6(12 \cdot 6)$ & 1. 0 Per $10 \%$ & NS & & 1.0 \\
\hline
\end{tabular}

or being from an ethnic minority group) were significant in both the 1981 cohort and the 1986 cohort. Four variables were significant predictors of acceptance in 1986 but not in 1981: applying after taking A levels, putting more medical schools on the application form, not being a mature applicant (over 21 on 30 September 1986), and bracketing choices on the application form. All except bracketing the choices of medical school or university showed trends towards significance in the 1981 cohort. Three variables (grade at O level, applying after A levels, and use of bracketing) were more important for selection in 1986 than in 1981.

Figure 1 shows that applicants from ethnic minority groups are less likely to be accepted than white applicants at all grades of A level achievement.

FIG 1-Percentage of white and non-white applicants accepted by any medical school in 1986 according to mean $A$ level grade achieved

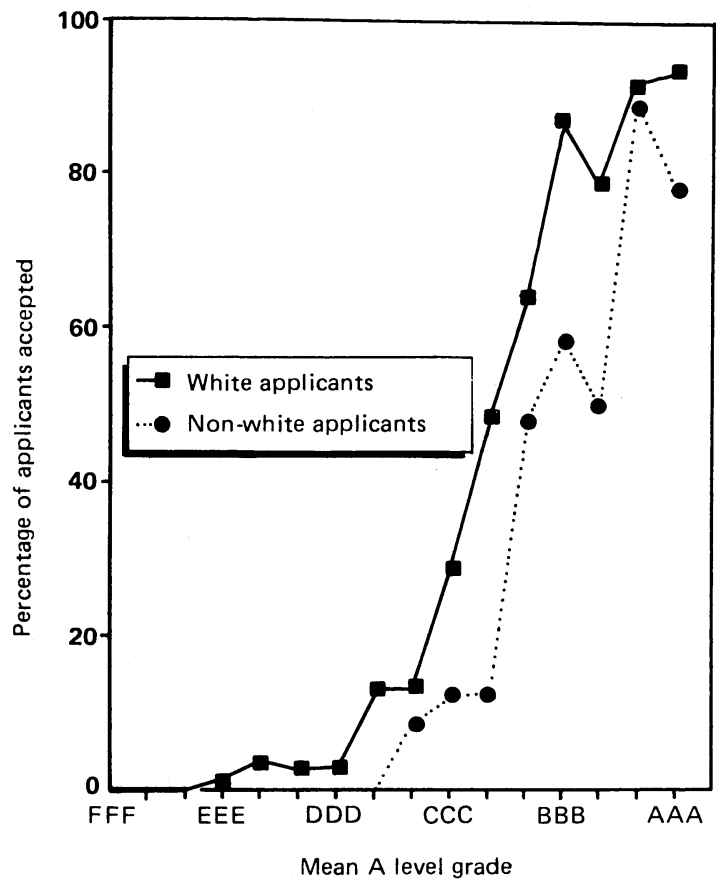

Table I shows for each of the ethnic groups the predicted proportion that would be accepted, given the overall differences in the grades at A level, the date of application, and the proportions that apply after A levels. Nearly $36 \%$ of non-white applicants were predicted to be accepted compared with an actual value of $27 \cdot 3 \%$. The proportional difference was similar in all ethnic subgroups.

\section{ROLE OF SHORTLISTING VARIABLES}

In the 1981 survey the relative disadvantage of ethnic minority applicants was rendered non-significant after taking into account the shortlister's assessments of academic ability, interests, and contribution to the community. ${ }^{3}$ A similar analysis for the 1986 cohort considered the additional predictive effect of the three shortlisting assessments in addition to grades at $\mathrm{O}$ and $\mathrm{A}$ levels, date of application, and application after A levels. This reduced the odds ratio for the disadvantage of applicants from ethnic minority groups from $2 \cdot 67$ to $2 \cdot 11$ ( $95 \%$ confidence interval $1 \cdot 44$ to 3.07$)$, which is still significant $(p<0.001)$. The relative disadvantage of minority candidates cannot therefore be explained entirely in terms of nonacademic aspects of the application form.

\section{DIFFERENCES BETWEEN INDIVIDUAL MEDICAL SCHOOLS}

We investigated the extent to which medical schools differ towards applicants from ethnic minorities by taking schools in turn, considering the fate of the applicants to St Mary's who had also applied to each particular medical school, and observing whether an offer was made by the school. We assessed the role of ethnic origin after taking into account those predictors of greater importance in the overall analysis - that is, mean $A$ level grade, mean $O$ level grade, date of application, and application after A levels, as well as the position that the school had been placed on the application form. Figure 2 shows the odds ratio for the disadvantage of applicants from ethnic minorities in obtaining offers at each medical school. The confidence intervals are too wide to make useful inferences about the role of ethnic group in selection at individual schools.

\section{Discussion}

In autumn 1985 St Mary's Hospital Medical School received applications from $24.7 \%$ of all home candidates who applied to the Universities Central Council on Admissions to study medicine; these people included $22.7 \%$ of all home students subsequently admitted to a medical school in the United Kingdom to study medicine.

Our 1986 audit of the selection of medical students confirmed the role of the seven variables found to be significant predictors in 1981. In addition, we found four additional predictors of success, one of which, the use of bracketing of choices on the application form, will not be a future predictor as the Universities 


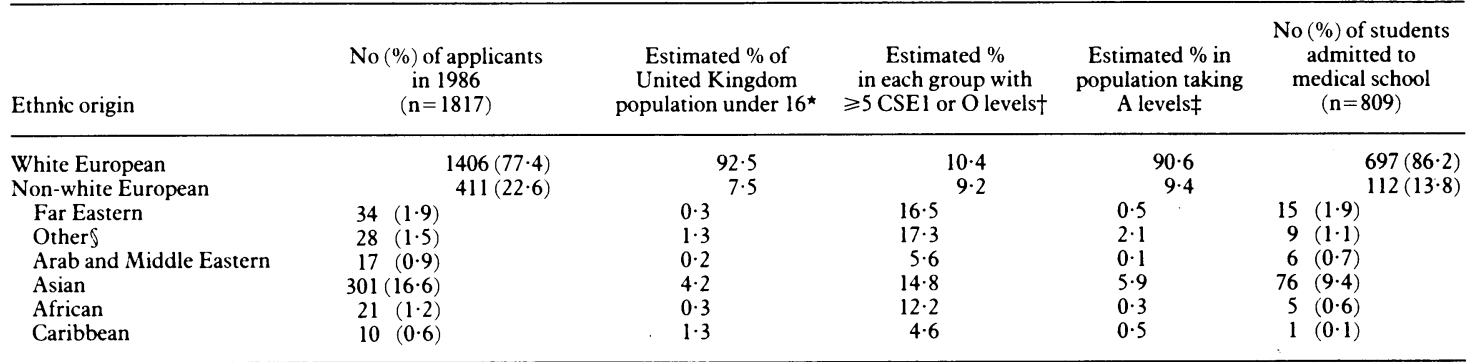

CSE $1=$ Certificates of secondary education grade 1

*Proportion of each ethnic group in population of United Kingdom from average data from labour force surveys, 1984-6, based on population under $16^{14}$ as ethnic minority populations are growing more quickly than non-minority populations."

†Percentage of children from different ethnic groups in Inner London Education Authority who gained five or more $\mathrm{O}$ levels or certificates of secondary education grade 1 in 1985 and $1986 . .^{\text {th }}$

$\ddagger$ Taken from estimated percentage of population in United Kingdom under 16 and estimated percentage in each group with five or more $\mathrm{O}$ levels or certificates of secondary education grade 1 to give proportions of group in population eligible to sit A level examinations (and hence potentially eligible to apply to medical school).

§Includes mixed parentage.

Central Council on Admissions has since discontinued rank ordering of choices, partly because it confers an unfair advantage to some applicants. ${ }^{13}$

The most important findings of this study concern groups, even after taking into account differences in achievement at $\mathrm{O}$ and $\mathrm{A}$ level, the date of application, and application after $A$ levels. In 1981 these differences could be explained in terms of differences in nonacademic factors perceived by shortlisters from the application form; in 1986 that was not entirely the case. Also by 1986 the proportion of candidates with nonEuropean surnames had doubled since 1981, rising

Our data are not conclusive evidence of discrimination by medical schools against non-white applicants. Medical students are selected on grounds broader than merely academic, and there is increasing public and professional pressure that this should be so. They are being admitted to a humane, caring profession: other criteria such as interest, initiative, enthusiasm, and an ability both to communicate and to empathise are also being assessed not only from the application form but in many cases also from interviews with applicants. Such measures might differ systematically among ethnic groups (and further analyses of questionnaires completed by applicants suggest that applicants from ethnic minority groups do indeed differ in many ways from others); although such differences might explain proved by a more extensive study.

People from ethnic minority groups form a higher proportion of medical school applicants than in the population overall (table III). Another study also showed that university entrants whose ethnic origin was South Asian were particularly likely to study medicine, science, and engineering. ${ }^{18}$ Table III additionally shows that the proportions of students admitted to medical school are closer to the proportion in the general population, except for a conspicuous deficit

FIG 2-Odds ratios for relative disadvantage of candidates from ethnic minority groups when compared with equivalently qualified white candidates at 27 British medical schools (ignoring three schools, in Scotland or Northern Ireland, which had too few applicants in our sample to allow any reasonable estimate of likelihood). Error bars indicate $95 \%$ confidence intervals for estimates the disadvantage of applicants from ethnic minority from $11 \cdot 2 \%$ to $22 \cdot 9 \%$. the differences we have observed, it could only be

of Caribbean entrants. In reporting these data we are aware that our "Asian" category is itself heterogeneous and that it has been found that many more students of East African and Indian origin enter university compared with those of Pakistani or Bangladeshi origin. ${ }^{19}$ Although applicants for medicine include a comparative excess of students from ethnic minority groups, the Race Relations Act 1976 does not allow positive or negative discrimination on the grounds that groups are over represented or underrepresented: each applicant should be considered on his or her own merits. Much more information is needed about how appropriate merits for entry to different professions are judged.

We thank Mrs Rosemary Boyd, Ms C Richards, Ms D Evans, Ms M Stylianides, and Mr C Gurney for their help in organising and running the study; $\mathrm{Mr} M \mathrm{~J}$ Hiscock, $\mathrm{Mr}$ S Morris, and the Universities Central Council on Admission for providing data on the destination of applicants; the A level examining boards for granting permission to examine A level results; the Universities Central Council on Admissions for providing the A level results in computer readable form; and Dr Diana N J Lockwood for help in classifying surnames. We thank the Economic and Social Research Council for funding the survey. Finally, we thank all the applicants who completed our long questionnaires.

1 Universities Central Council on Admissions. Statistical supplement to the twentyfourth report, 1985-6. Cheltenham: UCCA, 1987.

2 McManus IC, Richards P. Audit of admission to medical school. I. Acceptances and rejects. BrMed F 1984;289:1201-4.

3 McManus IC, Richards P. Admission to medical school. Br Med 7 1985;290 319-20.

4 Commission for Racial Equality. Medical schools admissions: report of a forma investigation into St George's Hospital Medical School. London: CRE, 1988.

5 Lowry S, Macpherson G. A blot on the profession. Br Med f 1988;296:657-8.

6 Collier J, Burke A. Racial and sexual discrimination in the selection of students to London medical schools. Medical Education 1986;20:86-9.

7 McManus IC, Maitlis SL, Richards P. Shortlisting of applicants from UCCA forms: the structure of pre-selection judgments. Medical Education (in press).

8 McManus IC, Richards P. Reliability of shortlisting in medical student selection. Medical Education (in press)

McManus IC, Richards P. Audit of admission to medical school. II. Shortlisting and interviews. Br Med f 1984;289:1288-90.

10 McManus IC. Medical students: origins, selections, attitudes and culture [MD thesis.] London: University of London, 1985.

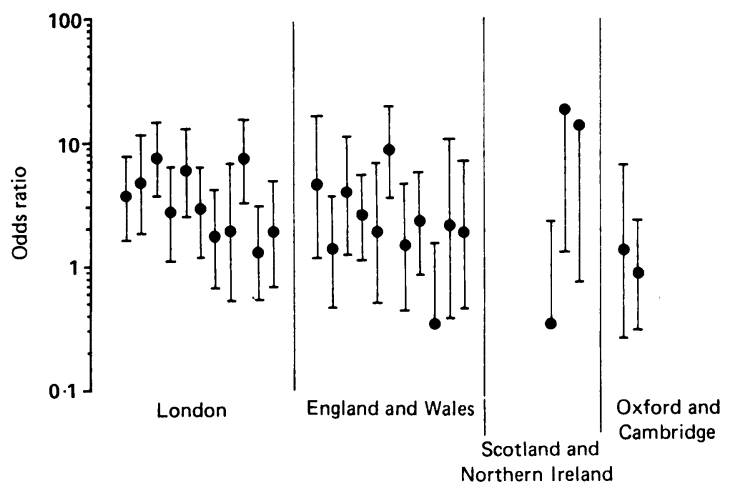

11 Anonymous. Sitistical pachage for the social sciences- $X$ : user's guide. New York: McGraw-Hill, 1983.

12 Baker RJ, Nelder JA. The GLIM system, release 3. Oxford: Numerical Algorithms Group, 1978

13 McManus IC, Richards P. Choice and ordering of medical school applications: cause for concern. Lancet 1987; ;i:33-5.

14 Shaw C. Latest estimates of ethnic minority populations. Population Trend 1988;51:5-8.

15 Population Statistics Division, OPCS. Ethnic minority populations in Great Britain. Population Trends 1986;46:18-21.

16 Inner London Education Authority. Ethnic background and examination results 1985 and 1986. London: ILEA, 1987.

17 Kysel F. Ethnic background and examination results. Educational Research 1988;30:83-9, 198.

18 Vellins S. South Asian students in British universities: a statistical note. New Community 1982;10:206-12.

19 Ballard R, Vellins S. South Asian entrants to British universities: a com parative note. New Community 1985;12:260-5.

(Accepted 3 February 1989) 